\title{
Vascular Redistribution for SIRT-A Quantitative Assessment of Treatment Success and Long-Term Analysis of Recurrence and Survival Outcomes
}

\author{
Philip Borg ${ }^{1} \quad$ Jen Jou Wong ${ }^{1} \quad$ Nicholas Lawrance $^{1} \quad$ Amarjot Chander $^{1} \quad$ jill Tipping ${ }^{2} \quad$ Jon Bell ${ }^{1}$ \\ Damian Mullan¹ Prakash Manoharan ${ }^{1}$ Steve Jeans² Jeremy Lawrance ${ }^{1}$
}

\footnotetext{
${ }^{1}$ Radiology Department, The Christie NHS Foundation Trust, Manchester, United Kingdom

${ }^{2}$ Medical Physics \& Engineering Department, The Christie NHS Foundation Trust, Manchester, United Kingdom
}

Address for correspondence Jen Jou Wong, MBChB, LLM, FRCR, Radiology Department, The Christie NHS Foundation Trust, Wilmslow Rd., Manchester M20 4BX, United Kingdom (e-mail: jenjou.wong@gmail.com).

J Clin Interv Radiol ISVIR 2019;3:89-97

\begin{abstract}
Aim Flow redistribution is not uncommonly performed as a treatment strategy to optimize delivery of radioembolization particles to the liver. We quantitatively evaluated the effect of vessel embolization to promote flow redistribution when performing selective internal radiation therapy (SIRT) for liver metastases, and assessed long-term outcomes of treatment.

Materials and Methods One hundred and fifty-eight SIRT procedures over an 8-year period were retrospectively reviewed. Twenty-three patients who underwent partial/ whole embolization of the left hepatic artery were compared to a control group of 18 patients who did not receive any hepatic embolization as part of their work up. Counts were measured for each patient on both the post- ${ }^{99 m}$ TcMAA injection, and the post- ${ }^{90} \mathrm{Y}$ microspheres injection imaging. Recurrence and survival rates were also measured.

Results A statistically significant shift in the right:left ratio between planning and treatment procedures was seen in patients who had vessel embolization in favor of the

Keywords

- embolization, therapeutic

- liver neoplasms

- microspheres

- retrospective studies

- survival rate embolized lobe $(p=0.014)$. There was no significant difference in the time to recurrence in the embolized lobes versus the nonembolized lobes. No significant difference in overall survival was detected between the two cohorts.

Conclusion To facilitate safe whole liver treatment, it is sometimes necessary to partially or completely occlude main or accessory hepatic arteries. This study shows that the success of flow redistribution strategies can be quantitatively measured, and there is no adverse impact on time to recurrence or overall survival outcomes.
\end{abstract}

\section{Introduction}

Transcatheter hepatic arterial radioembolization with Yttrium $90\left({ }^{90} \mathrm{Y}\right)$ microspheres is an established, effective treatment modality for patients with unresectable primary and metastatic liver-dominant malignancy and a life expectancy of above 3 months. ${ }^{1-7}$ Liver tumors above $3 \mathrm{~mm}$ have a predominantly arterial vascularization so that intra-arterial administration of microparticles containing ${ }^{90} \mathrm{Y}$ become trapped in the arterioles and capillaries of the tumor. ${ }^{8.9}{ }^{90} \mathrm{Y}$ is

\section{received}

February 20, 2019

accepted after revision

May 27, 2019
DOI https://doi.org/

10.1055/s-0039-1694091

ISSN 2457-0214. a pure beta emitter that has a radiotherapeutic effect on an area of approximately $1 \mathrm{~cm}$ surrounding the site where it is deposited. This results in a highly targeted selective intra-arterial brachytherapy which minimizes the dose to normal liver parenchyma compared to external beam radiotherapy. ${ }^{90}$ Y microspheres are available as either glass or resin microspheres. In this study, only resin microspheres (SIR-Spheres, Sirtex Medical) were used.

The aim of selective internal radiation therapy (SIRT) is to deliver radioactive particles to treat all of the identified 
intrahepatic tumor and minimize delivery of particles to the normal liver parenchyma and avoid any extrahepatic deposition. An angiographic workup is performed first to determine hepatic arterial vascular supply and detect any anatomical variations. Vascular anatomy, and therefore the flow dynamics of the hepatic arterial blood supply can be variable. Aberrant vessels arising from the superior mesenteric trunk (replaced right hepatic artery [RHA]), segmental hepatic segment IV vessels, and left hepatic artery (LHA) arising from or in combination with the left gastric artery (LGA) are frequent findings. ${ }^{10,11}$ Any extrahepatic vessels of hepatic artery origin are coil occluded to avoid complications from delivery of radioactive particles to organs outside the liver. There is consensus in the literature that the gastroduodenal artery (GDA) and the right gastric artery (RGA) should be prophylactically embolized. ${ }^{1-3,7}$ Some authors also recommend cystic artery embolization to minimize exposure of the gallbladder to radioactive particles; however, this is not the practice at our institution. ${ }^{12}$

In our experience, partial or complete coil embolization of the LHA, or of accessory hepatic arteries, is sometimes required to prevent extrahepatic deposition of ${ }^{90} \mathrm{Y}$ microspheres or to facilitate treatment by limiting the number of treatment catheter positions required. This has the theoretical potential to undertreat embolized areas of the liver; however, it is well recognized that the hepatic interlobar arterial collateral system or communicating arcade helps to reestablish arterial perfusion to liver segments that have undergone embolization. ${ }^{13,14}$

We set out to quantitatively determine the amount of radioactive particle deposition in hepatic segments that have undergone coil embolization of the hepatic artery supplying that segment. Particle deposition in patients who had not undergone coil embolization to the hepatic arterial supply was also measured as a control group. The GDA and the RGA were routinely embolized in all patients. The ${ }^{90} \mathrm{Y}$ microspheres were administered into the proper hepatic artery or replaced RHA as a single dose or in divided doses into the hepatic arterial branches of the proper hepatic artery.

Other studies have looked into the treatment effect on hepatic lesions in embolized segments by measuring change in size according to the RECIST criteria on follow-up imaging, ${ }^{15}$ and comparing decrease in standardized uptake value on pre- and posttreatment fluorodeoxyglucose-positron emission tomography (PET). ${ }^{16}$ One study measures size of lesions (mRECIST) on follow-up imaging as well as qualitative evaluation by radiologists of uptake of ${ }^{99 \mathrm{~m}} \mathrm{Tc}$ and ${ }^{90} \mathrm{Y}$ on single-photon emission computed tomography (SPECT)/ computed tomography (CT). ${ }^{17}$ From our review of the literature, there are no publications that have looked at quantitative measurement of counts from a region of interest (ROI) on SPECT/CT imaging as a method of determining actual deposition of radioactive particles.

\section{Methods and Materials}

All SIRT cases at our institution between 2008 and 2014 were reviewed. Cases with unfavorable anatomy that had undergone coil occlusion of any hepatic branch artery were selected. Cases that had not undergone any coil embolization were selected as a control group. All cases were discussed at a multidisciplinary meeting attended by interventional radiologists, clinical oncologists, and hepatobiliary surgeons.

The workup angiogram involved interrogation of the celiac axis and superior mesenteric arteries and their branches. The GDA and RGAs were always coil embolized to occlusion when possible. Hepatic arteries were coil embolized when safe treatment sites could not be obtained, for instance, when the RGA could not be embolized and a distal treatment position was not possible in a segment 4 or LHA. Replaced left hepatic arteries from the LGA were coil embolized.

One hundred and fifty $\mathrm{MBq}( \pm 10 \%)$ Technetium-99m labeled macroaggregated albumin ( ${ }^{99 \mathrm{~m} T c-M A A)}$ in $1.5 \mathrm{~mL}$ was delivered during the angiograms. This simulates the distribution of the SIR spheres during the treatment. ${ }^{99 \mathrm{~m} T c-M A A}$ was injected at the intended treatment sites.

The patients were then transferred to the nuclear medicine department for imaging within 20 minutes, before the ${ }^{99 m} \mathrm{mc}-\mathrm{MAA}$ could dissociate. All patients were imaged using a dual-head gamma camera (GE Infinia Hawkeye 4 with $9 \mathrm{~mm}$ crystals), and whole body (WB) planar and hybrid SPECT/ CT acquisitions were performed according to the standard protocols at the time which enabled identification and localization of extrahepatic activity. The presence of extrahepatic tracer accumulation, in particular related to the stomach and intestine, is a contraindication to treatment if the injection site cannot be modified or the relevant vessels embolized.

Planar images were used to calculate pulmonary shunt fractions in line with the manufacturer's recommendations. Dose modification is advised for patients with lung shunts of greater than $10 \%$. However, this was not necessary in our group of patients.

There was a 2- to 4-week interval between injection of ${ }^{99 m} \mathrm{mc}-\mathrm{MAA}$ and ${ }^{90} \mathrm{Y}$ microspheres. A WB planar and SPECT/ $\mathrm{CT}$ acquisition of the abdomen and pelvis was performed 24 hours after treatment, using the bremsstrahlung emission of ${ }^{90} Y$, to determine tracer distribution within the liver.

Using GE Xeleris imaging software, an initial analysis was made on the reconstructed SPECT/CT images of the pre-SIRT MAA and post-SIRT bremsstrahlung liver images. The SPECT/ CT images reconstruction included attenuation correction derived from the registered CT, and scatter correction. Seven patients were excluded from data analysis as the CT component could not be performed on the pre- and/or posttreatment scans (due to a period of malfunctioning of the SPECT/ CT scanner).

A ROI was selected for a single metastasis in the right lobe and a single metastasis in the left lobe of the liver. The lesions were selected following review of either a contemporaneous contrast-enhanced PET/CT, CT, or magnetic resonance imaging of the liver, to ensure that the areas of tracer uptake corresponded to actual lesions. This was done for each patient on the post- ${ }^{99 \mathrm{~m}} \mathrm{Tc}-\mathrm{MAA}$ workup imaging and the post- ${ }^{90} \mathrm{Y}$ microspheres treatment imaging, having first registered all scans so that the same ROI could be applied to the same regions before and after therapy. 
We compared the posttherapy change in the ratio of uptake right:left lobes of the liver in patients who had partial embolization of the hepatic artery at the time of embolization and after ${ }^{90} \mathrm{Y}$ delivery. The acquisition and reconstruction settings of all MAA scans and bremsstrahlung scans were identical to ensure that any changes in right:left ratios are due to redistribution and not reconstruction artifacts.

Cases that had not undergone SPECT post-99mTcMAA and ${ }^{90} Y$ microspheres injection, or where clearly identifiable disease in both the right and left lobes of the liver could not be identified, were excluded from the study.

Analysis was made on the reconstructed axial slices of gamma $\left({ }^{99 \mathrm{~m}} \mathrm{Tc}\right)$ and bremsstrahlung $\left({ }^{90} \mathrm{Y}\right) \mathrm{SPECT}$ imaging using Xeleris imaging software ( - Fig. 1). Counts were measured in ROIs of $1 \mathrm{~cm}^{2}$, which were selected at sites of disease in the right and left lobes of the liver in the embolized and nonembolized groups. Nuclear medicine scans were reviewed to assess the distribution of radiopharmaceutical after the test and treatment delivery sessions. Follow-up scans and reports were then reviewed for each patient to identify time points of recurrence and death. Statistical analysis was performed using SPSS (version 23 for Macintosh, IBM). Paired samples $t$-test was performed to look for significant differences in the change in the right:left ratio in radiopharmaceutical uptake between the planning and posttreatment scans. KaplanMeier survival curves were formed, with log-rank tests calculated to determine any significant difference $(p<0.05)$ in time to local recurrence between the right and left lobes of embolized patients, and overall survival between the embolization and control groups. Qualitative measures of response were categorized and potential relationships with independent variables investigated by binomial logistic regression. Finally, an assessment of agreement between the qualitative and quantitative indicators of response was performed by Cohen's kappa calculation.

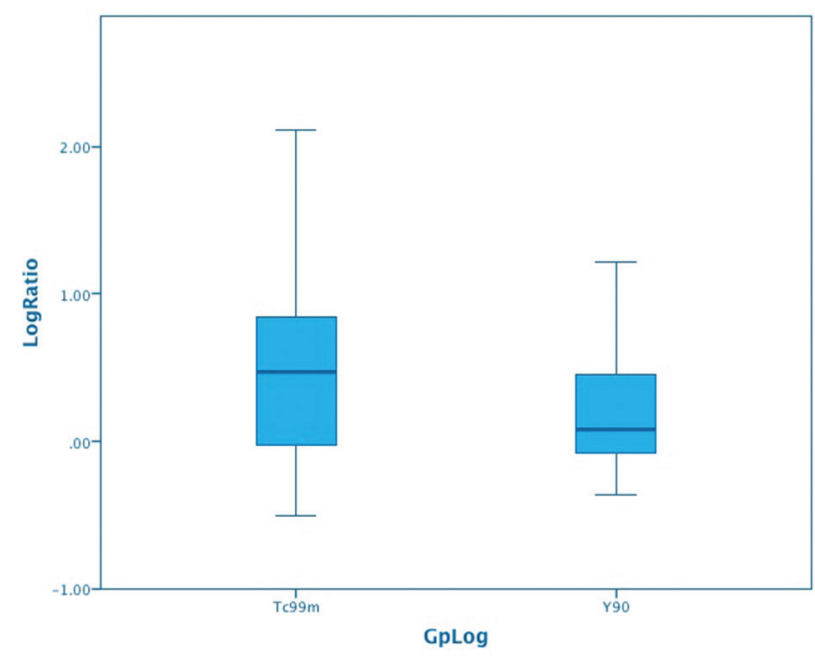

Fig. 1 Box plot with 95\% confidence intervals. The median log ratios of the ${ }^{90} \mathrm{Y}$ right:left counts is closer to zero compared to the pretreatment ${ }^{99 m}$ Tc-MAA log ratios, in keeping with equalizing of the right:left distribution of tracer between the two procedures in the embolized group.

\section{Results}

Thirty-three patients who underwent partial/whole embolization of the LHA were identified. Out of these, 10 patients were excluded from the quantitative data set to produce the right:left uptake ratios, as SPECT imaging was not available $(n=6)$ or patients were not suitable for data analysis as disease could only be reliably assessed on the SPECT scan in one lobe due to resolution $(n=4)$, leaving a total of 23 patients with complete data ( - Tables 1 and $\mathbf{2}$ ). A total of 4 years' follow-up scans were analyzed.

A further 33 patients who did not receive any embolization as part of their workup for SIRT were identified as

Table 1 Cohort characteristics (embolization arm)

\begin{tabular}{|c|c|c|c|}
\hline \multicolumn{4}{|l|}{ Demographics } \\
\hline \multirow[t]{3}{*}{ Gender } & & & $p=0.768$ \\
\hline & Male & 21 & \\
\hline & Female & 20 & \\
\hline Age & & $62(43-77)$ & $p=0.670$ \\
\hline \multirow[t]{6}{*}{ Tumor type } & & & $p=0.980$ \\
\hline & CRLM & 24 & \\
\hline & $\begin{array}{l}\text { Cholangiocar- } \\
\text { cinoma }\end{array}$ & 5 & \\
\hline & Breast & 4 & \\
\hline & $\begin{array}{l}\text { Neuroendo- } \\
\text { crine }\end{array}$ & 4 & \\
\hline & Other & 4 & \\
\hline \multirow[t]{3}{*}{$\begin{array}{l}\text { Flow redistribu } \\
\text { tion performec }\end{array}$} & & & \\
\hline & Yes & 23 & $p=0.041$ \\
\hline & No & 18 & \\
\hline \multirow[t]{5}{*}{$\begin{array}{l}\text { Treatment } \\
\text { location }\end{array}$} & & & \\
\hline & Right hepatic & 15 & \\
\hline & $\begin{array}{l}\text { Right + "mid- } \\
\text { dle" hepatic }\end{array}$ & 2 & \\
\hline & $\begin{array}{l}\text { Right + left } \\
\text { hepatic }\end{array}$ & 1 & \\
\hline & $\begin{array}{l}\text { Replaced right } \\
\text { hepatic }\end{array}$ & 5 & \\
\hline \multirow[t]{3}{*}{ Complications } & & & \\
\hline & Deaths & 0 & \\
\hline & $\begin{array}{l}\text { Nontarget } \\
\text { embolization }\end{array}$ & 1 & \\
\hline
\end{tabular}

Abbreviation: CRLM, colorectal liver metastases. 
Table 2 Embolization arm patient characteristics

\begin{tabular}{|c|c|c|c|c|c|c|}
\hline Patient & Pathology & $\begin{array}{l}\text { Tumor vol } \\
(\mathrm{R})\end{array}$ & $\begin{array}{l}\text { Tumor } \\
\text { vol (L) }\end{array}$ & $\begin{array}{l}\text { Embolized } \\
\text { vessels }\end{array}$ & Reason for embolization & Complications \\
\hline 1 & CRC & $>10 \leq 20$ & $>30 \leq 40$ & GDA, Rep LHA & $\begin{array}{l}\text { Replaced LHA from left gastric, to pre- } \\
\text { vent three box treatment }\end{array}$ & \\
\hline 2 & CRC & $>10 \leq 20$ & $<10$ & LHA & $\begin{array}{l}\text { Short common trunk with LG, RG, GDA, } \\
\text { safe treatment position in left not } \\
\text { possible }\end{array}$ & \\
\hline 3 & CRC & $>20 \leq 30$ & $>10 \leq 20$ & Acc LHA & $\begin{array}{l}\text { Replaced accessory LHA from left gas- } \\
\text { tric, too small for treatment position }\end{array}$ & \\
\hline 4 & CRC & $>10 \leq 20$ & $>20 \leq 30$ & GDA, Rep LHA & $\begin{array}{l}\text { Replaced LHA from left gastric, to pre- } \\
\text { vent three box treatment }\end{array}$ & \\
\hline 5 & CRC & $>10 \leq 20$ & $>10 \leq 20$ & GDA, Rep LHA & $\begin{array}{l}\text { LHA and LG common origin from CA, to } \\
\text { prevent three box treatment }\end{array}$ & \\
\hline 6 & Breast & $>20 \leq 30$ & $<10$ & GDA, Rep LHA & $\begin{array}{l}\text { Replaced LHA from left gastric, for one } \\
\text { box/position treatment }\end{array}$ & \\
\hline 7 & Cholangio & $>10 \leq 20$ & $>20 \leq 30$ & GDA, Rep LHA & $\begin{array}{l}\text { Replaced LHA from left gastric, collat- } \\
\text { eral flow from right seen, for one box/ } \\
\text { position treatment }\end{array}$ & \\
\hline 8 & Cholangio & $<10$ & $>50$ & GDA, LHA & Extrahepatic shunts from LHA seen & \\
\hline 9 & CRC & $>10 \leq 20$ & $<10$ & GDA, LHA & RG from LHA not accessible & \\
\hline 10 & Breast & $>30 \leq 40$ & $<10$ & GDA, Rep LHA & $\begin{array}{l}\text { Replaced LHA from LG, cross flow } \\
\text { from right seen, for one box/position } \\
\text { treatment }\end{array}$ & $\begin{array}{l}\text { Significant reflux, } \\
\text { reduced dose given }\end{array}$ \\
\hline 11 & CRC & $>10 \leq 20$ & $>20 \leq 30$ & GDA, Rep LHA & $\begin{array}{l}\text { Replaced LHA from left gastric, prevent } \\
\text { three box/position treatment }\end{array}$ & \\
\hline 12 & CRC & $>10 \leq 20$ & $>20 \leq 30$ & GDA, LHA & $\begin{array}{l}\text { To flow redistribute, prevent three box/ } \\
\text { position treatment }\end{array}$ & \\
\hline 13 & CRC & $>10 \leq 20$ & $>20 \leq 30$ & GDA, LHA & $\begin{array}{l}\text { To flow redistribute, prevent three box/ } \\
\text { position treatment }\end{array}$ & \\
\hline 14 & CRC & $<10$ & $<10$ & GDA, LHA & $\begin{array}{l}\text { Right gastric from LHA not possible to } \\
\text { access }\end{array}$ & \\
\hline 15 & CRC & $>10 \leq 20$ & $<10$ & $\begin{array}{l}\text { GDA, Rep LHA, } \\
\text { segment IV }\end{array}$ & $\begin{array}{l}\text { Replaced LHA from left gastric not easi- } \\
\text { ly accessible for safe treatment position }\end{array}$ & \\
\hline 16 & Cholangio & $>10 \leq 20$ & $>10 \leq 20$ & $\begin{array}{l}\text { Acc LHA, LHA, } \\
\text { GDA }\end{array}$ & $\begin{array}{l}\text { RG from LHA not accessible, small } \\
\text { accessory LH not appropriate for treat- } \\
\text { ment position }\end{array}$ & \\
\hline 17 & CRC & $>10 \leq 20$ & $<10$ & GDA, LHA & $\begin{array}{l}\text { Treated from Replaced common, LHA } \\
\text { small with dual origins from replaced } \\
\text { CHA and CA }\end{array}$ & \\
\hline 18 & Cholangio & $>10 \leq 20$ & $>50$ & LHA, GDA & $\begin{array}{l}\text { Atrophic left lobe, dominant cross- } \\
\text { supply from right }\end{array}$ & \\
\hline 19 & Pancreatic & $<10$ & $<10$ & $\begin{array}{l}\text { GDA, RG, Rep } \\
\text { LHA }\end{array}$ & $\begin{array}{l}\text { Replaced LHA with communicating } \\
\text { arcade to RHA, to avoid three box/posi- } \\
\text { tion treatment }\end{array}$ & $\begin{array}{l}\text { Y90 greater curve } \\
\text { stomach, } 0.5 \% 4 \mathrm{MBq} \text { - } \\
\text { not seen on planning }\end{array}$ \\
\hline 20 & Breast & $>10 \leq 20$ & $<10$ & LHA & $\begin{array}{l}\text { LHA short trunk with GDA and supradu- } \\
\text { odenal braches, not able to completely } \\
\text { embolize }\end{array}$ & $\begin{array}{l}\mathrm{x} 1 \text { GDA coil snared as } \\
\text { encroached into } \mathrm{CHA}\end{array}$ \\
\hline 21 & Bladder & $>30 \leq 40$ & $<10$ & LHA, GDA & $\begin{array}{l}\text { Dominant right sided disease, for one } \\
\text { box/position treatment }\end{array}$ & \\
\hline 22 & CRC & $>20 \leq 30$ & $>10 \leq 20$ & $\begin{array}{l}\text { Rep LHA, RG, } \\
\text { GDA }\end{array}$ & $\begin{array}{l}\text { Replace LHA from left gastric, for one } \\
\text { box/position treatment }\end{array}$ & \\
\hline 23 & CRC & $<10$ & $<10$ & LHA, GDA, RG & LHA too small for treatment position & \\
\hline
\end{tabular}

Abbreviations: Acc, accessory; CHA, common hepatic artery; Cholangio, cholangiocarcinoma; CRC, colorectal cancer; GDA, gastroduodenal artery; LG, left gastric; Rep LHA, replaced left hepatic artery; RG, right gastric.

Note: Pathology, tumor volume, and embolized vessels in the treatment group. 
a control group (group B). Out of these, 15 patients were excluded from the data set as they were not suitable for data analysis since disease was only identified in one lobe. The rest of the workup and treatment were identical in both groups, including routine embolization of nonhepatic, nontarget vessels, usually the GDA and RGA. Embolization was achieved with pushable coils in all cases, with flow cessation within the artery confirmed by digital subtraction angiography. Embolization was well tolerated in all cases. There was one inadvertent, partial coil deployment into the common hepatic artery. This did not appear to result in any clear flow limitation, and did not impact on treatment delivery.

Forty-one patients ( 21 male, 20 female) with a mean age of 62 years old (range: 43-77) at time of treatment were included. Mean survival from treatment was 493 days (range: $51-1,869)$. Histology of treated metastases were 58\% (24) colorectal, 12\% (5) cholangiocarcinoma, 10\% (4) breast, 10\% (4) neuroendocrine, $2 \%$ (1) choroidal melanoma, 2\% (1) ampullary papillary carcinoma, $2 \%$ (1) lung, and $2 \%$ (1) pancreas.

The LHA was the most commonly embolized artery in this patient cohort. In 10 cases, the LHA was found to be replaced via the LGA. In 11 cases, the proper LHA was embolized for a variety of reasons (see table). Fifty-one vessels were coiled in total across 23 patients. Fifteen treatments were delivered from the proper RHA, 5 from a replaced RHA from the superior mesenteric artery, 2 from both the RHA and "middle" hepatic arteries, and 1 from both a RHA and LHA. There was one case in the embolization group that had nontarget embolization of ${ }^{90} \mathrm{Y}$ to the stomach that was not anticipated by the planning ${ }^{99 m}$ Tc-MAA scan. This carried an approximate proportion dose delivery of $0.5 \%$ to the stomach. No side effects from the nontarget embolization were reported. Twenty-five vessels that contributed to the hepatic vasculature but were felt unsuitable or difficult to treat from were coiled, potentially reducing what may have been prolonged or repeat treatment sessions involving these vessels.

A comparison of count ratios between the left and right lobes within the embolized group was made, comparing the scan immediately after vessel embolization and the test dose administration, and the post- ${ }^{90} \mathrm{Y}$ treatment scan. The $\log _{10}$ ratios were then calculated in order to normalize the data. Paired samples $t$-test was performed on the before and after embolization count ratios. Thirteen cases demonstrated a change in ratio reflecting an increase in flow to the embolized left lobe. This represented over half of the cases available for full quantitative analysis, overall the box plot showed a significant difference in the right:left ratio of activity $(p=0.041$ ) from the time of the planning angiogram and test dose delivery when compared to the posttreatment ${ }^{90}$ Y PET scan ( - Fig. 1).

In the long-term follow-up, there was no significant difference in the overall survival (death by any cause) between the embolization arm, and the comparison, case-matched group that had no hepatic artery vessel embolized ( $p=0.493,-$ Fig. 2 ).

Further, Kaplan-Meier survival and log-rank analysis was performed on the embolization group to detect any difference in time to recurrence between the right and left lobes of patients, and no statistically significant difference could be found ( $p=0.799$, - Fig. 3 ).
Binomial logistic regression was then performed to see if there was any relationship between quantitative and qualitative response against age, sex, diagnosis, and tumor volume (which was categorized into 10\% incremental categories to aid regression analysis). There was no statistically significant relationship of qualitative or quantitative response to embolization in either manner to the recorded covariates

The qualitative results of the distribution of treatment were recorded by reviewing the posttreatment nuclear scans. Grading categories from 1 to 4 (none, poor, moderate, and good) were assigned based on the interpretation of the nuclear medicine scan relating to the distribution of ${ }^{90} \mathrm{Y}$ ( - Figs. $\mathbf{4}$ and $\mathbf{5}$ ).

Seventeen patients were rated to have good redistribution in the qualitative assessment. Cohen's kappa was performed to the level of agreement between the subjective and objective tests of redistribution in the 23 embolized patients. Although this showed fair agreement $(\mathrm{k}=0.258),{ }^{18}$

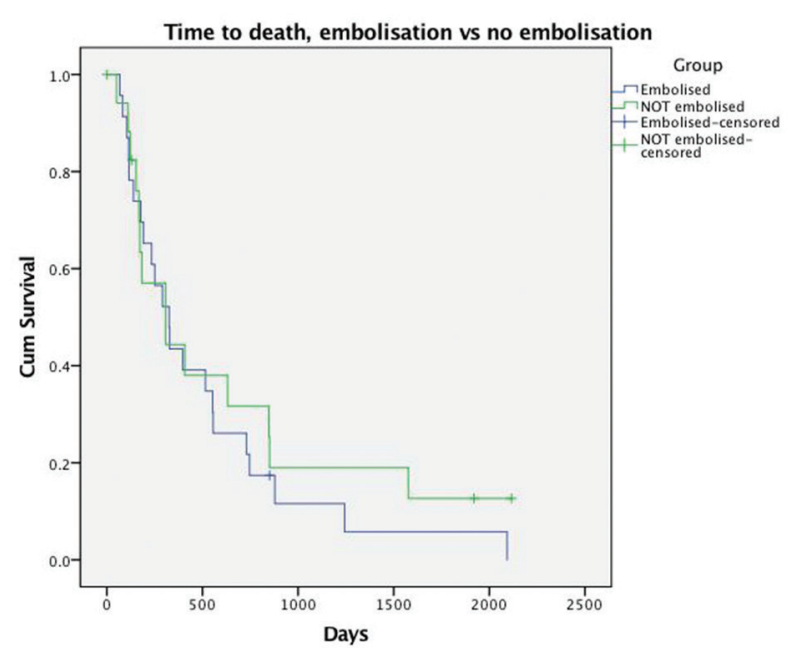

Fig. 2 Kaplan-Meier curve showing time to death (all causes, days) of the embolized and nonembolized groups $(p=0.493)$.

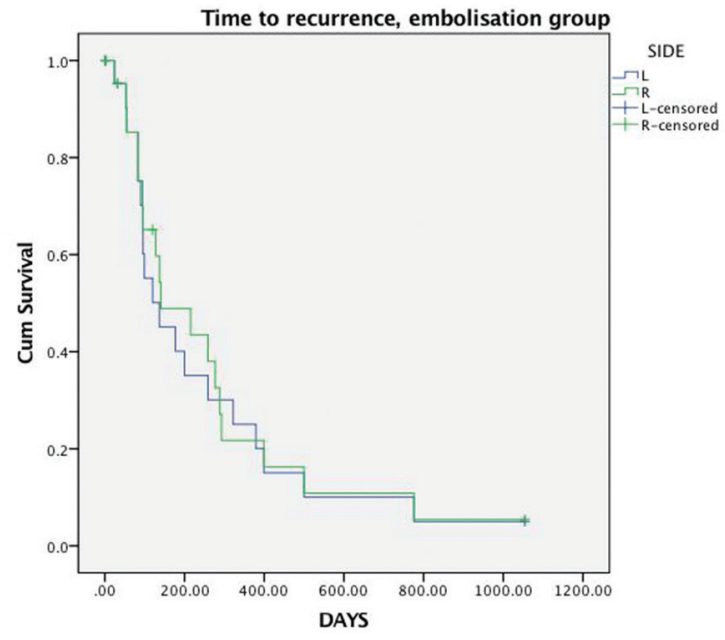

Fig. 3 Kaplan-Meier curve comparing time to recurrence between the right and left lobes from the embolization arm $(n=23)$. There was no statistically significant difference between the right and left lobes $(p=0.799)$. 
this did not reach statistical significance. An example case of a flow-redistributed patient is shown in -Figs. 6 and 7.

\section{Discussion}

Vascular redistribution of intrahepatic blood flow is not uncommonly performed where there is aberrant arterial anatomy arising from the hepatic arterial supply, or from extrahepatic vessels providing supply to intrahepatic tumors. In the presence of multiple potential treatment locations in major hepatic vessels, it may be undesirable to have more than two or three treatment delivery positions due to the risk of radioactive spillage during catheter exchanges, or due to the challenges of accurately assessing segmental dosimetry when preparing the radiopharmaceutical. The presence

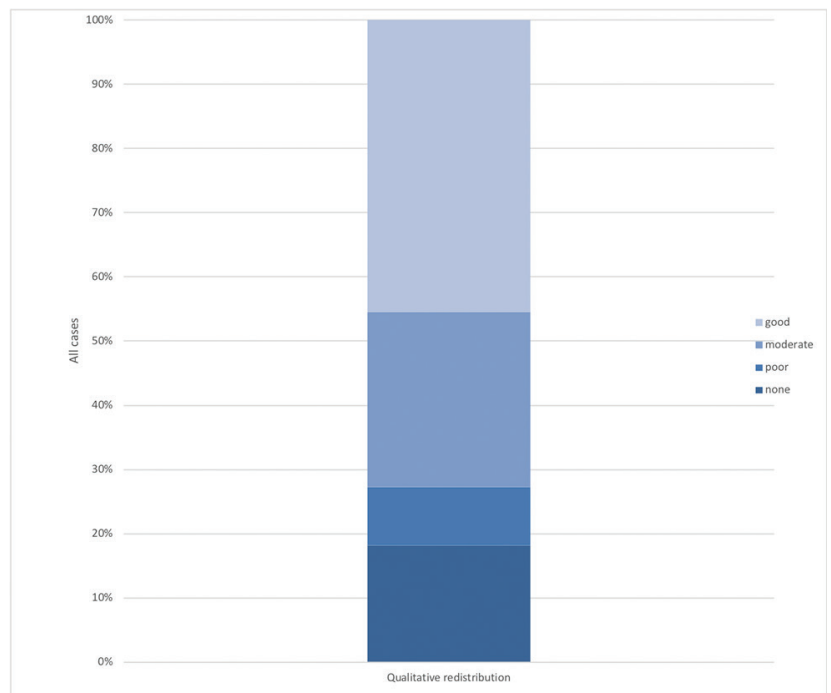

Fig. 4 Qualitative assessment of redistribution in the embolization arm. The majority of cases showed a qualitative change in vascular redistribution on analysis of the right:left ratio changes. of extrahepatic branches, depending on their origin, may prohibit the delivery of treatment in cases where selective cannulation is not possible and the threat of nontarget embolization is increased. A main hepatic vessel embolization in an attempt to promote flow redistribution from other viable treatment positions may be a preferred tactic, rather than complete abandonment of SIRT treatment as an option in otherwise eligible patients. It is recognized that SIRT practice has evolved considerably since its introduction to the United Kingdom, and treatment strategies have also changed over time within our institution, one of the first in the United Kingdom to perform radioembolization. While some of the treatment strategies employed in this patient group may be treated differently today, it was considered an ideal cohort for long-term follow-up of the effects of vessel embolization and vascular redistribution. Our analysis therefore concentrates on the immediate and long-term effects of vessel embolization rather than the specific strategy chosen, and that the information yielded can help inform future treatments in which redistribution is being considered as a tactic.

Not all patients in the embolization cohort demonstrated a quantitative equalization of the right:left counts ratios between the workup and posttreatment scans, although overall the embolization group as a whole showed a statistically significant shift in the distribution ratio between scans. Additionally, there appeared to be a fair correlation between the quantitative and qualitative response, with the majority of patients showing concordance between these two methods of assessment. However, we would note that certain limitations of study and methodology might have impacted our results.

It is acknowledged that dosimetry techniques have advanced significantly since the inception of SIRT and are still undergoing continual evolution. The cases included in our study are from the earliest era of treatments in the United Kingdom where bremsstrahlung SPECT was commonly used

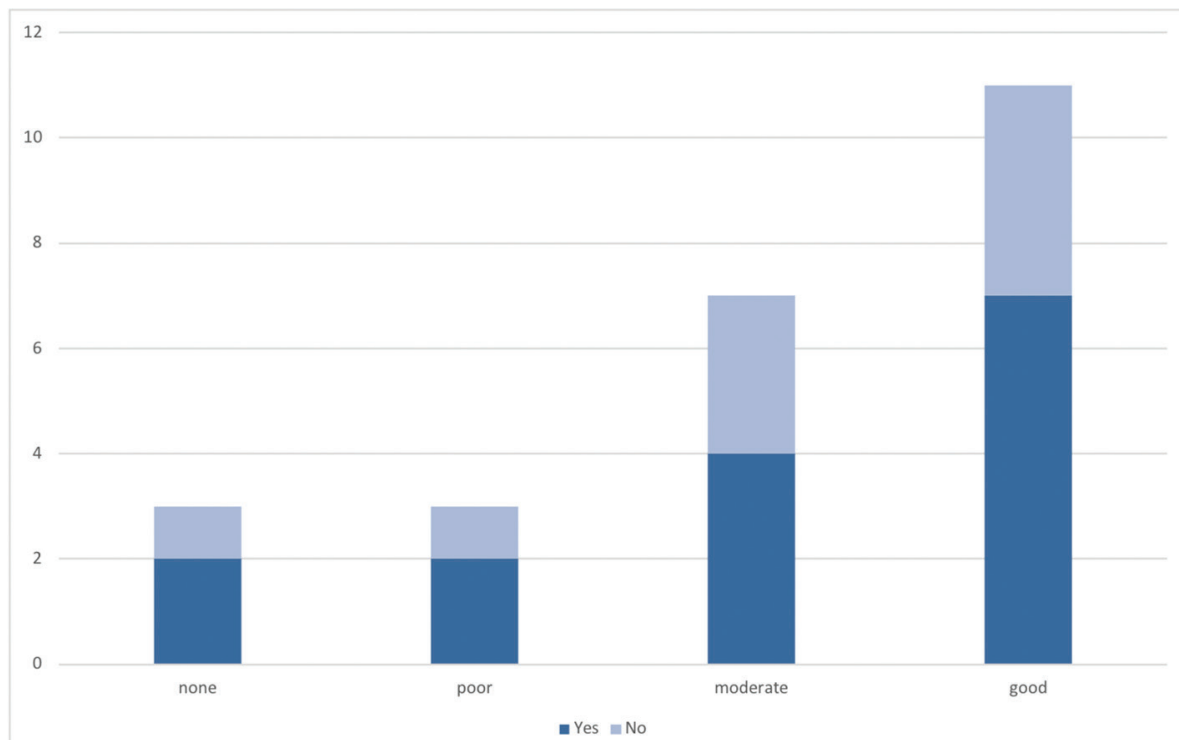

Fig. 5 Qualitative and quantitative redistribution in the embolization arm. Each column showing the qualitative rating of flow redistribution is broken down into subgroups showing that a majority proportion had a corresponding quantitative change in the right:left flow ratio. 


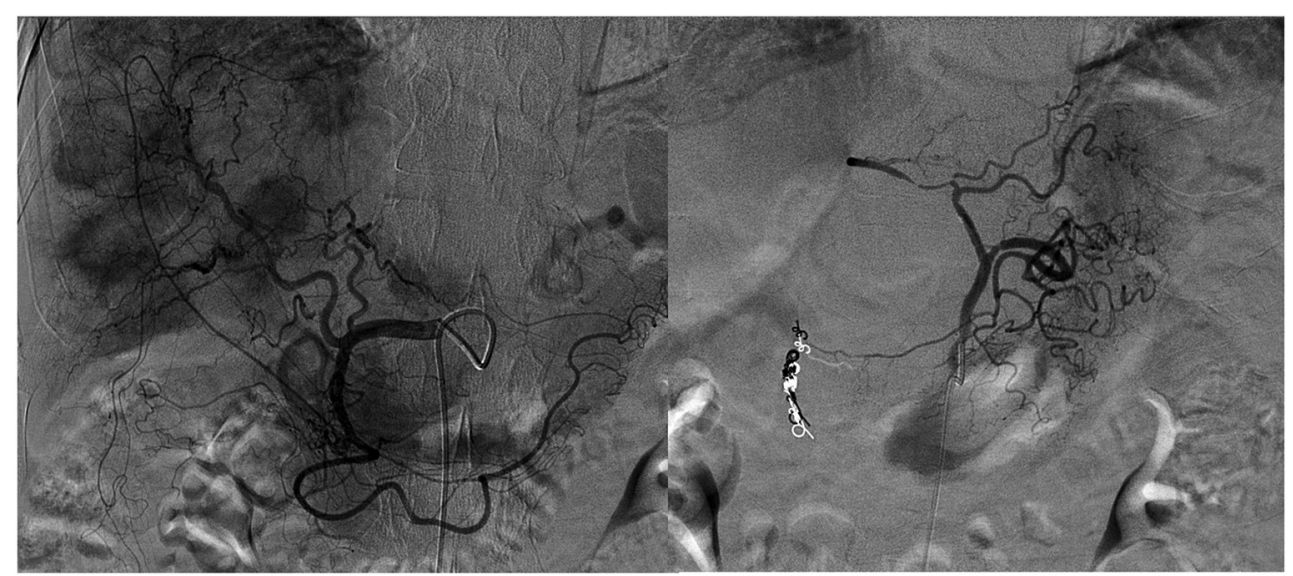

Fig. 6 Angiogram of an example embolization cohort patient. Common hepatic angiogram (left panel) shows a right hepatic artery, and a smaller left hepatic supplying segment 3. An accessory left hepatic artery from the left gastric is seen (right panel). This was embolized to allow two treatment positions in the native right and left hepatic arteries.

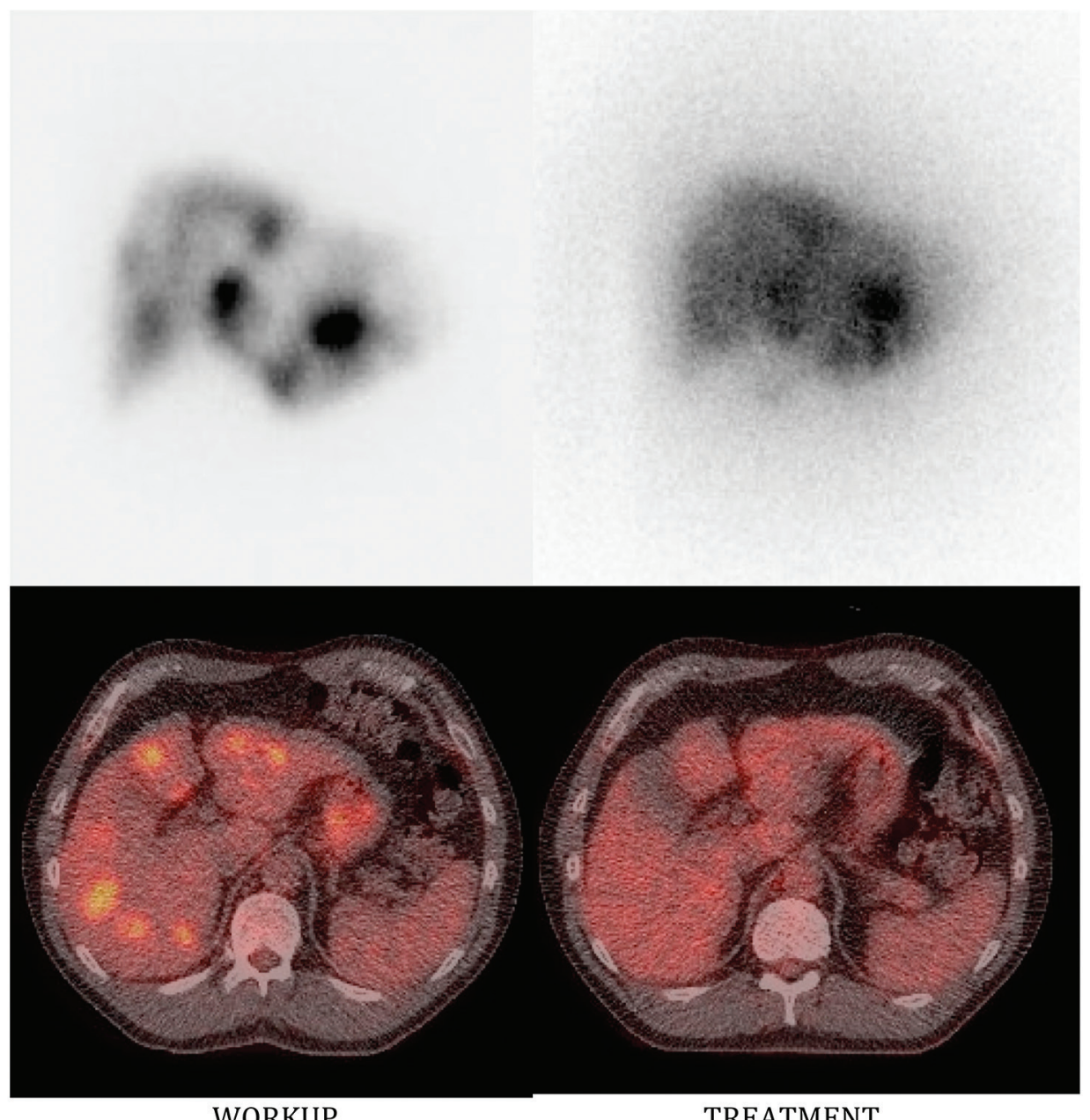

Fig. 7 Pre- and post-selective internal radiation therapy (SIRT) imaging in the same example patient. The workup bremsstrahlung single-photon emission computed tomography (SPECT) (top-left) shows relative photopenia in the left lobe of the liver, with more equal distribution after accessory left hepatic artery embolization and SIRT delivery (top right). The pretreatment positron emission tomography (PET)-computed tomography (CT) shows disease in both lobes of the liver (bottom left), with good metabolic response bilaterally on follow-up imaging (bottom right). 
in dosimetry assessment. Although both methods are considered to provide satisfactory accuracy of biodistribution, PET is now more commonly performed which has been shown to demonstrate superior spatial resolution. Ideally, more than one index lesion in each lobe would have been assessed and quantified to add accuracy to the study although this was limited by the fact that not all patients had more than one tumor in each lobe. Our attempts to quantitatively characterize dose ratios was limited by the spatial resolution of SPECT performed in this cohort of patients, and limited the potential target lesions available for assessment. This is likely to have impacted on the level of agreement found between the objective and subjective methods of assessing redistribution. However, despite the limitations of the quantitative analysis, the statistically significant change in ratios is further supported by our 4-year long-term follow-up of local recurrence rates between the right and left lobes in the embolized group (with no difference in time to recurrence), and the survival comparisons showing that embolization did not impact on time to death by any cause when compared to the nonembolized cohort.

Although cost was not a measured outcome of interest in this study, the possibility of potential savings is raised. Treatment strategies that require more than a single treatment position occasionally prove onerous to perform in a single sitting if vascular anatomy is complex. Performing flow redistribution to reduce the potential number of treatment positions and sessions can therefore result in a saving in angiography suite, ward, and medical staff time (the current National Health Service tariff for radioembolization procedure costs, minus the radiopharmaceutical, is $£ 3,394){ }^{19}$

The concept of flow redistribution has been studied prior to SIRT in the context of local chemotherapy infusion. Bengmark and Rosengren ${ }^{20}$ documented one of the earliest attempts to prove the ability of the liver to compensate for devascularization at either the lobar level, or even after complete surgical ligation of the common hepatic and any other hepatic arterial supply. They performed follow-up aortography in 10 cancer patients showing collateralization from the pancreaticoduodenal and phrenic arteries in all cases. Chuang and Wallace ${ }^{13}$ published a case series of 10 patients receiving hepatic arterial chemotherapy for various malignancies, embolizing a variety of replaced or aberrant hepatic arteries with a mixture of gelfoam and coils to optimize treatment from a single catheter position. Immediate angiographic evidence of the opening of collateral vessels to the embolized areas was recorded, and serial catheter angiograms were performed over several months showing sustained development of intrahepatic collaterals. Civalleri et $a^{21}$ went on to quantitatively demonstrate the effect in 4 patients that had surgical ligation of either the right or left main hepatic arteries, followed by ${ }^{99 m}$ Tc-MAA infusion from the common hepatic. They showed equalization of the distribution of ${ }^{99 m} \mathrm{Tc}-\mathrm{MAA}$ between the initial postoperative scan and at a repeat liver perfusion scan 15 days later.

In more recent literature pertinent to SIRT, Abdelmaksoud et $\mathrm{a}^{22}$ sought to show intrahepatic collateralization to tumors after embolization of extrahepatic vessels supplying them.
Thirty-five patients' outcome were reviewed, 25 of which scintigraphy data were available, although this and angiographic data were only qualitatively analyzed. Their high success rate of intrahepatic collateralization after selective embolization of extrahepatic supply to tumors was as high as $96 \%$ when look at biodistribution nuclear scanning alone, $94 \%$ if evaluated by cross-axial follow-up imaging. However, this analysis was in selected patients only, excluding those who had uniform progressive disease. Our quantitative and qualitative analysis included all patients eligible for inclusion in the study on an intention-to-treat basis. Lauenstein et $\mathrm{al}^{23}$ reviewed the SPECT/CT scans of 27 patients that had a middle of left segmental artery embolization as part of SIRT workup. Of the 11 patients that did not demonstrate immediate SPECT evidence of flow redistribution, 8 of these eventually did show redistribution, making a total of 24 patients who were successfully flow redistributed. No quantitative analysis or long-term response to treatment follow-up was mentioned in this study.

While there is increasing confidence in experienced centers to forego vessel embolization, it may still be necessary in certain circumstances where aberrant vasculature is encountered. When it cannot be guaranteed that access to these vessels would be easily achieved in the treatment session, an extrahepatic branch cannot be embolized, or if it is felt be to practically onerous to have several treatment positions, we feel our study with 4 years of follow-up data adds to the current evidence that in selected cases, main hepatic arterial branch embolization can be safely performed to promote intrahepatic collateralization, without detriment to the longterm efficacy of SIRT.

\section{Authors' Contributions}

P. Borg - Concept design, study lead, data collection, and literature review.

J. Wong - Data collection, statistical analysis, discussion, and literature review.

A. Chander - Data collection and nuclear medicine analysis.

J. Tipping - Data collection and nuclear medicine analysis.

S. Jeans - Data collection.

J. Bell - Paper review and critical analysis.

D. Mullan - Paper review and critical analysis.

J. Lawrance - Paper review and critical analysis.

P. Manoharan - Data collection and nuclear medicine analysis.

\section{Conflicts of Interest}

There are no conflicts of interests to declare by any of the authors.

\section{References}

1 Salem R, Thurston KG. Radioembolization with 90Yttrium microspheres: a state-of-the-art brachytherapy treatment for primary and secondary liver malignancies. Part 1: technical and methodologic considerations. J Vasc Interv Radiol 2006;17(8):1251-1278

2 Salem R, Thurston KG. Radioembolization with 90yttrium microspheres: a state-of-the-art brachytherapy treatment for 
primary and secondary liver malignancies. Part 2: special topics. J Vasc Interv Radiol 2006;17(9):1425-1439

3 Salem R, Thurston KG. Radioembolization with yttrium-90 microspheres: a state-of-the-art brachytherapy treatment for primary and secondary liver malignancies: part 3: comprehensive literature review and future direction. J Vasc Interv Radiol 2006;17(10):1571-1593

4 Kennedy A, Nag S, Salem R, et al. Recommendations for radioembolization of hepatic malignancies using yttrium-90 microsphere brachytherapy: a consensus panel report from the radioembolization brachytherapy oncology consortium. Int J Radiat Oncol Biol Phys 2007;68(1):13-23

5 Young JY, Rhee TK, Atassi B, et al. Radiation dose limits and liver toxicities resulting from multiple yttrium-90 radioembolization treatments for hepatocellular carcinoma. J Vasc Interv Radiol 2007;18(11):1375-1382

6 Braat AJ, Smits ML, Braat MN, et al. 90. Y hepatic radioembolization: an update on current practice and recent developments. J Nucl Med 2015;56(7):1079-1087

7 Vesselle G, Petit I, Boucebci S, Rocher T, Velasco S, Tasu JP. Radioembolization with yttrium-90 microspheres work up: practical approach and literature review. Diagn Interv Imaging 2015;96(6):547-562

8 Donato P, Coelho P, Rodrigues H, et al. Normal vascular and biliary hepatic anatomy: 3D demonstration by multidetector CT. Surg Radiol Anat 2007;29(7):575-582

9 Ackerman NB, Hechmer PA, Kondi ES. The blood supply of experimental liver metastases. V. Increased tumor perfusion with epinephrine. Am J Surg 1980;140(5):625-631

10 van den Hoven AF, Smits ML, de Keizer B, van Leeuwen MS, van den Bosch MA, Lam MG. Identifying aberrant hepatic arteries prior to intra-arterial radioembolization. Cardiovasc Intervent Radiol 2014;37(6):1482-1493

11 Tohma T, Cho A, Okazumi S, et al. Communicating arcade between the right and left hepatic arteries: evaluation with CT and angiography during temporary balloon occlusion of the right or left hepatic artery. Radiology 2005;237(1):361-365

12 McWilliams JP, Kee ST, Loh CT, Lee EW, Liu DM. Prophylactic embolization of the cystic artery before radioembolization: feasibility, safety, and outcomes. Cardiovasc Intervent Radiol 2011;34(4):786-792
13 Chuang VP, Wallace S. Hepatic arterial redistribution for intraarterial infusion of hepatic neoplasms. Radiology 1980;135(2):295-299

14 Gunji H, Cho A, Tohma T, et al. The blood supply of the hilar bile duct and its relationship to the communicating arcade located between the right and left hepatic arteries. Am J Surg 2006;192(3):276-280

15 Bilbao JI, Garrastachu P, Herráiz MJ, et al. Safety and efficacy assessment of flow redistribution by occlusion of intrahepatic vessels prior to radioembolization in the treatment of liver tumors. Cardiovasc Intervent Radiol 2010;33(3):523-531

16 Karunanithy N, Gordon F, Hodolic M, et al. Embolization of hepatic arterial branches to simplify hepatic blood flow before yttrium 90 radioembolization: a useful technique in the presence of challenging anatomy. Cardiovasc Intervent Radiol 2011;34(2):287-294

17 Spreafico C, Morosi C, Maccauro M, et al. Intrahepatic flow redistribution in patients treated with radioembolization. Cardiovasc Intervent Radiol 2015;38(2):322-328

18 Landis JR, Koch GG. The measurement of observer agreement for categorical data. Biometrics 1977;33(1):159-174

19 NHS Improvement, National tariff payment system 2018-19. Available at https://improvement.nhs.uk/resources/national-tariff-1719/\#h2-tariff-documents. Accessed May 14, 2019

20 Bengmark S, Rosengren K. Angiographic study of the collateral circulation to the liver after ligation of the hepatic artery in man. Am J Surg 1970;119(6):620-624

21 Civalleri D, Scopinaro G, Simoni G, et al. Starch microsphere-induced arterial flow redistribution after occlusion of replaced hepatic arteries in patients with liver metastases. Cancer 1986;58(9):2151-2155

22 Abdelmaksoud MH, Louie JD, Kothary N, et al. Embolization of parasitized extrahepatic arteries to reestablish intrahepatic arterial supply to tumors before yttrium-90 radioembolization. J Vasc Interv Radiol 2011;22(10):1355-1362

23 Lauenstein TC, Heusner TA, Hamami M, et al. Radioembolization of hepatic tumors: flow redistribution after the occlusion of intrahepatic arteries. RoFo Fortschr Geb Rontgenstr Nuklearmed 2011;183(11):1058-1064 